\title{
Effects of Swirl Number of the Nozzle of the Pulverized Coal Gasifier on Flow Field and Combustion Characteristics
}

\author{
Xuedong Liu ", Baixian Li and Wenming Liu \\ School of Mechanical Engineering. Changzhou University, Changzhou 213164, China \\ *Corresponding author
}

\begin{abstract}
The numerical simulation of multiphase combustion flow field in a pulverized coal gasifier with one single nozzle is conducted by using the method of two dimensional asymmetric swirl model. Based on the eddy-dissipation-concept model, the calculation process includes volume reaction and surface reaction which can simulate the turbulent combustion with multiple mechanisms. By changing the swirl number of the nozzle, a series of parallel simulations are conducted to collect the information on shape and distribution characteristics of reversed flow and flame. The results show that: the flow field inside this gasifier is mainly composed of a central recirculation zone and an external recirculation zone; a lager swirl number can lead to a sharp decline on axial velocity, which means for the one hand it can enhance the particle residence time, but for the other hand it cause a formation of the "no reaction area" filled with coal on the top of gasifier; when the swirl number is under 1.4, the flame showed in an awl shape and the temperature of entire gasifier is too high to gasify; when the swirl number is over 1.6, the hightemperature area exists near the top of gasifier and the flame shows in a flat petal shape, which is easy to turn the flame back to the nozzle; by using the Gauss curve to fit the scatter points, we can obtain a perfect swirl number 1.4.
\end{abstract}

Keywords-gasifier; swirl number; combustion characteristics; flow field; numerical simulation

\section{INTRODUCTION}

Due to the merits of high rate of coal conversion and great adaptability to mass production and coal species, the entrained flow gasifier is widely used in coal chemical industry[1]. Currently, at home and abroad the mainstream entrained flow gasification technologies are divided as pulverized coal gasification technology and coal water slurry gasification technology. The former includes the Shell gasification technology, GSP gasification technology, Prenflo gasification technology and GE (Texaco) gasification technology; the latter contains Global E-Gas gasification technology, multi-nozzle gasification technology, multi-stage gasification technology [2].

Given the types of turbulent combustion models, numerical simulation researches on gasification process can be generally classified into three categories: PDF model, EBU model and EDC model. By using the EDC model, Xu et al. [3] simulated homogeneous chemical reactions inside a GSP gasifier, and established a complete flow model of multiphase turbulent reaction in order to simulate the thermal gasification process; Based on a presumed PDF model, Wu et al. [4] conducted a three-dimensional numerical simulation to detailedly study its operating characteristics and the particle motion in the gasifier, which finally helped to analyze the effects of the concentration of coal water slurry [O] / [C] atomic ratio and particle size on gasification process; Zhou et al. [5] chosen the PDF model and the partial instantaneous equilibrium model to study the gasification performance under variable operating conditions; With the EBU model, Chen et al. [6] implemented a numerical simulation of a two-stage pulverized coal gasifier, and drew a conclusion to the impacts of throat diameter and swirl ratio on axial velocity distribution, temperature distribution and component concentration distribution; Moreover, by using the similar approaches, Watanabe et al. [7] carried out a series of numerical simulations with different operating parameters to gain a high gasification efficiency.

Based on the previous research, the coupling simulation of the discrete phase and continuous phase inside the one single nozzle coal gasifier which is now under operaion in a certain plant was conducted. By using a swirling axisymmetric boundary, the velocity field distribution, flame shape and particle residence time is studied. This methond that turne a $3 \mathrm{D}$ problem into $2 \mathrm{D}$ and also include the $3 \mathrm{D}$ characteristic parameter like tangential velocity provids a new idea for the simplified CFD numerical simulation.

\section{PHYSICAL AND COMPUTATIONAL METHOD}

\section{A. Object and Process Conditions}

The research object is a pulverized coal gasifier with one single nozzle. Table 1 shows the operating parameters. The top-mounted nozzle has four channels, which are placed in way of concentric circles. Figure 1 shows the brief nozzle structure. Oxygen is injected in a swirling way through channel I and II; water steam is injected through channel IV; the pressurized pulverized coal particles are injected through III with the carrying medium of $\mathrm{CO}_{2}$. Pulverized coal particles undego a series of complex reactions of pyrolysis, devolatilization, combustion and gasification, and finally produces the synthesis gases $\left(\mathrm{CO}\right.$ and $\left.\mathrm{H}_{2}\right)$. Meanwhile, solid slag constantly gathers on the membrane to protect silicon carbide layer and membrane wall from thermal corrosion. 
TABLE I. OPERATION PAREMERTERS OF GASIFIER

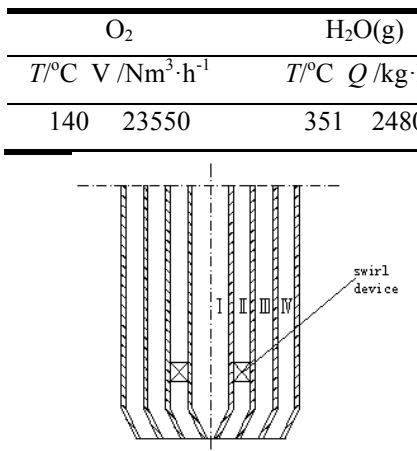

(a)

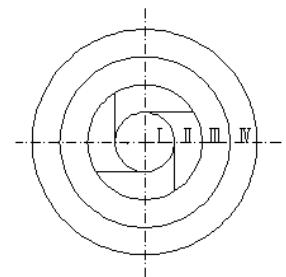

(b)
FIGURE I. BRIEF DIAGRAM OF NOZZLE

\section{B. Grid Meshing}

Figure 2 shows computing grid meshed by ANSYS ICEM software. Structured quadrilateral body-fitted mesh was adopted to mesh the whole calculation domain, which was divided into different blocks and was set lots of nodes along the edges of blocks (250 nodes were set along the height direction of the model, and 80 nodes the diameter direction). Considering strong swirl characteristics in the gasifier, center grids near the upper section of the gasifier was refined. In order to ensure both the calculation precision and speed, grid independence was studied with grid numbers of 14400, 31000 and 72800 . The grid of 31000 was finally used for computing analysis. $99 \%$ of the grid quality value was larger than 0.95 , and the minimum angle is less than $45^{\circ}$. Both perfectly met the requirements of CFD calculation.

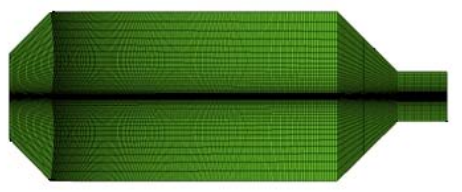

FIGURE II. GASIFIER GRID

\section{Computational Method}

The nozzle inlet used velocity inlet boundary condition, and keep the speed $60 \mathrm{~m} \cdot \mathrm{s}^{-1}$ invariant; By ignoring the radial velocity, the nozzle swirl number $S$ is defined as ratio of tangential velocity and axial velocity; By changing swirl number( $S=0.2,0.6,1.2,1.4,1.6,1.8), 6$ parallel simulations were conducted; the gasifier outlet boundary is pressure outlet, and the gauge pressure is $0 \mathrm{MPa}$; the wall temperature are defined as constant value $1600 \mathrm{~K}$; The pressure term is PRESTO, and the momentum and turbulence equations are used in QUICK.

The entire calculation process can be roughly divided into two steps: the first step is to receive a preliminary converged solution to an initiatory simulation without reactions; the second step is to regain a second order upwind converged solution by adding the species transport equations, the interacting reactions of discrete particles and the continuous flow, and an ignition process.

\section{MATHEMATICAL MODEL}

\section{A. Turbulence Model}

Using Realizable $k-\varepsilon$ two-equation model to simulate the gas phase turbulent flow field. This new $k-\varepsilon$ eddy viscosity model consists of a new model dissipation rate equation and a new realizable eddy viscosity formulation. The former is based on the dynamic equation of the mean-square vorticity fluctuation at large turbulent Reynolds number. And the latter is based on the realizability constraints - the positivity of normal Reynolds stresses and the Schwarz' inequality for turbulent shear stresses. This model suits the gasifier with a single nozzle mounted on the top better than the previous standard $\mathrm{k}-\varepsilon$ two-equation model, because its taking into account of the impact of swirling flow and pressure gradient ${ }^{[8]}$.

\section{B. Volatile Combustion Reaction}

The EDC model can be used to study detailed chemical mechanisms of the turbulence combustion. The model was first proposed by Magnussen in 1981, and its basic idea is that the gas-phase chemical reaction consists of the two components: in the microscopic turbulence structure, molecules collide constantly with each other and the reaction process is controlled by chemical kinetics; in the large eddy region near the microscopic turbulence structure, chemical reactions are taken place right after the completion of the mixture, the time of which is much longer than that of reactions, and the reaction process is controlled by the mixing rate.

\section{Coke Combustion Reaction}

A multi-step reaction model was used to calculate surface reactions. The surface reactions are also called heterogeneous gasification reactions that mainly account for the generation of $\mathrm{CO}$ and $\mathrm{H} 2$. So it is of great importance to the formation of flow field, temperature field and the concentration field of synthesis gas. However, the actual chemical reaction in the gasifier does not reach an equilibrium state, and reaction process is more complex. In order to fullfill the success of the simulation and reflect as accurately as possible the real gasification process, the surface reactions were simplified as follows: $\mathrm{C}(\mathrm{s})+\mathrm{O}_{2} \rightarrow \mathrm{CO} ; \quad \mathrm{C}(\mathrm{s})+\mathrm{CO}_{2} \rightarrow \mathrm{CO} ; \quad \mathrm{C}(\mathrm{s})+\mathrm{H}_{2} \rightarrow \mathrm{CH}_{4}$; $\mathrm{C}(\mathrm{s})+\mathrm{H}_{2} \mathrm{O} \rightarrow \mathrm{CO}+\mathrm{H}_{2}$

\section{RESULTS AND DISCUSSION}

\section{A. Influence of Swirl Number on the Reversed Flow}

Figure 3 shows the particle pathlines with different swirl numbers. As is shown in the figure, the recirculation zone inside a gasifier mainly consists of a central recirculation zone $\mathrm{A}$ and an external recirculation zone $\mathrm{B}$. The former is located just beneath the nozzle and close to central axis; the latter lay in the upper corner, and with swirling radius constantly increasing, the mixing flow impacts the membrane wall and are rebounded in some angle. Those 
rebounded upward form the corner external recirculation zone, but those rebound downward finally form the central recirculation zone.

When the swirl number $S$ varies from 0.2 to 1.8 , the jet diffusion angle of the flow increases. Initially, the increased swirl number has a positive effect on the formation of central recirculation zone A: when $S=0.2$, there is no obvious central recirculation zone; when $0.6 \leq S \leq 1.4$, there is a significant central backflow; when $S \geq 1.6$, there is no obvious central recirculation zone again. The larger the number $S$ is, the less the external recirculation zone form.

As is shown in Figure 3 (f), the central recirculation circle and corner recirculation circle has a line of tangency which forms a certain angle with the axial line. A double angle is defined as jet diffusion angle. Figure 4 shows jet diffusion angles with different swirl numbers. With the swirl number becoming larger, the jet diffusion angle gets larger accordingly. When $S=1.8$, the angle reaches a maximum value $115^{\circ}$.Moreover, when $S \geq 1.4$, the zone B is clearly suppressed in the corner area.
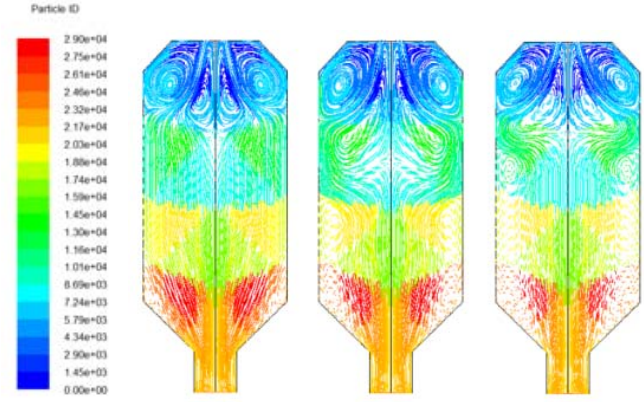

(a) $S=0.2$

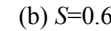

(c) $S=1.2$
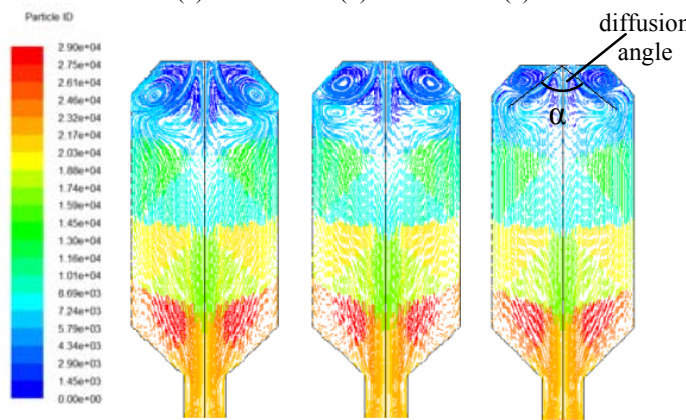

(d) $S=1.4$

(e) $S=1.6$

(f) $S=1.8$

FIGURE III. PARTICLE PATHLINES

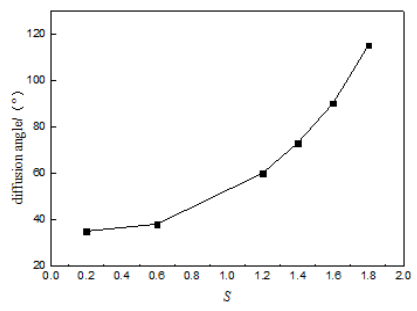

FIGURE IV. JET DIFFUSION ANGLES WITH DIFFERENT SWIRL NUMBERS

\section{B. Influence of Swirl Number on Axial Velocity}

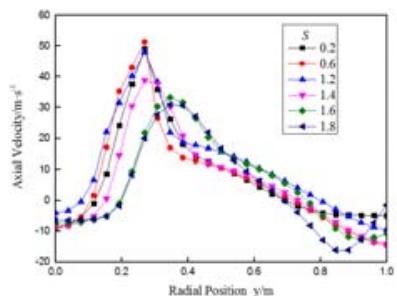

FIGURE V. RADIAL DISTRIBUTION OF AXIAL VELOCITY 0.3M AWAY FROM TOP NOZZLE WITH DIFFERENT SWIRL NUMBERS

Figure 5 shows the radial distribution of axial velocity $0.3 \mathrm{~m}$ away from top nozzle with different swirl numbers. Due to the existence of central recirculation zone and external recirculation zone, velocity near the axis and wall are negative. With the increasing of swirl number, the flow intensity increases continuously, and the maximum axial velocity near the central axis is continuously attenuated, and gradually transforms into the tangential swirl velocity, which is in agreement with the experimental results of the reference[9]. The attenuated axial velocity weakens the pushing power of the gas ,and then particles stay near the corner, which is called" no reaction area".

\section{Influence of Swirl Number on Particle Residence Time}

A longer the particle residence time in the reaction area has an important influence on coal conversion rate ${ }^{[10]}$. From Figure 6 , with the swirl number becoming larger, the average residence time and shortest residence time becomes larger firstly and then becomes smaller. When the swirl number is 1.4 , the maximum of the average residence time and shortest residence time is $2.89 \mathrm{~s}$ and $0.92 \mathrm{~s}$. In order to obtain a more accurate swirl number, a continuous function is used to fit scatters in the range of $[0.2,1.8]$. Figure 7 shows Gauss curve fitting the scatters, in which the best swirl number of the maximum average residence time is slightly left to 1.4.

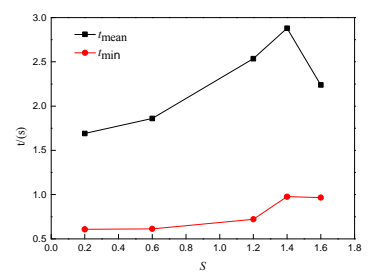

FIGURE VI. AVERAGE RESIDENCE TIME AND SHORTEST RESIDENCE TIME WITH DIFFERENT SWIRL NUMBERS

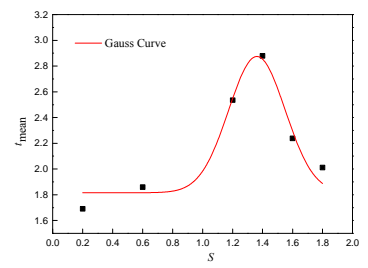

FIGURE VII. GAUSS CURVES FITTING THE AVERAGE RESIDENCE TIME 


\section{Influence of Swirl Number on Combustion Field}

Figure 8 shows the temperature distribution in the gasifier. The highest temperature in the gasifier is $2900 \mathrm{~K}$ located in the flame centre.

When the swirl number $S \leq 0.6$, the flame is in an awl shape and the temperature of reaction area is $2700 \mathrm{~K} \sim 2900 \mathrm{~K}$, which is reasonable, but that of gasification area and outlet is $2300 \mathrm{~K}$, which is not reasonable. Because the gasification reaction is endothermic, and the entire gasification is in a relative cold environment.

When the swirl number $S \geq 1.4$, the flame is in an petal shape, and the whole $2300 \mathrm{~K}$ area moves upward to the reaction area, which is close to the real situation.

As is shown in Figure 8 (f), the line connecting the axis apex and the farthest point of the flame forms a angle with the axial. A double angle is defined as flame diffusion angle. Figure 9 shows flame diffusion angles with different swirl numbers. With the swirl number becoming larger, the flame diffusion angle gets larger accordingly. The minimum angle is $45^{\circ}$ and the maximum is $110^{\circ}$. Moreover, when $\mathrm{S} \geq 1.4$, the flame shape is more flat.

The increased diffusion angle on the one hand prolongs the residence time of reaction mixture, and improves the reaction efficiency, but on the other hand leads to a "no reaction area" and turns the hot species back to the nozzle which keep nozzle outlet a high temperature.
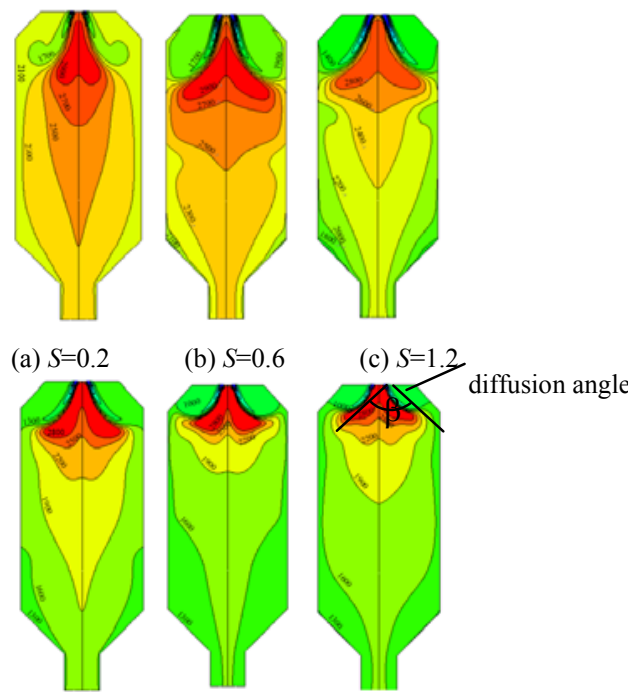

(d) $S=1.4$

(e) $S=1.6$

(f) $S=1.8$

FIGURE VIII. TEMPERATURE DISTRIBUTION OF GASIFER

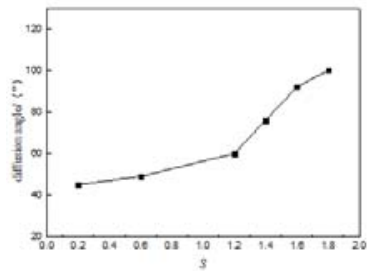

FIGURE IX. FLAME DIFFUSION ANGLES WITH DIFFERENT SWIRL NUMBERS

\section{CONCLUSIONS}

In this paper, by choosing Realizable $k-\varepsilon$ two-equation model to simulate the gas-phase turbulent flow field, EDC model to simulate the turbulent combustion., and changing the swirl number $S$, some conclusions are drawn as follows:

(1) The internal flow field of gasifier with a swirling nozzle has an obvious swirling characteristic; It mainly consists of a central recirculation zone and an external recirculation zone. An increased swirl number has a positive effect on the formation of central recirculation.

(2) When swirl number $\mathrm{S}<1.4$, the flame is in an awl shape; when the swirl number $\mathrm{S} \geq 1.4$, the central flame is in an petal shape.

(3) As the swirl number increases, the axial velocity declines significantly, on the one hand it prolongs the average residence time and shortest residence time, on the other hand it leads to the formation of "no reaction area". By using Gauss curves, a relative best swirl number of this gasifier can be obtained, which is 1.4

\section{References}

[1] K. P. Xia , H. P . Chen, X. H. Wang, S. H. Zhang and B. Gao, et al. "Entrained-bed Coal Gasification Technology and Its Development Tendency," J. Coal Conversion, vol.28, pp. 69-73, 2005.

[2] F. C. Wang, G. S. Yu, X. Gong, Lu, H.F. and Wang, Y.F. et al. "Research and Development of Large-scale Coal Gasification Technology," J. Chemical Industry and Engineering Progress. vol. 28, pp.173-180, 2009.

[3] J. L. Xu, H. F. Liu, J. Wang, B. Huang and Y. J. Ma, et al. "Numerical Simulation of Coal Gasification in GSP Coal Gasifier," J. Chemical Engineering, vol. 39, pp. 56-65, 2011.

[4] Y. X. Wu, J. S. Zhang, M. M. Wang, G. X. Yue and J. F. LV, et al. "Analysis of Gasification Performance of a Texaco Gasifier Based on Presumed PDF Model," J. Proceedings of the CSEE, vol. 27, pp. 57-62, 2007.

[5] J. H. Zhou, J. P. Kuang, Z. J. Zhou, J. Z. Liu and K. F. Cen, "Numerical Simulation for Pulverized Coal Gasifier's Fluid Flow Characteristic on Cold and Hot Condition," J. Proceedings of the CSEE, vol. 27, pp.30-35, 2007.

[6] C. Chen, M. Horio, T. Kojima, "Use of Numerical Modeling in the Design and Scale-up of Entrained Flow Coal Gasifier," J. Fuel, vol. 80, pp.1513-1523, 2001.

[7] H. Watanabe and M. Otaka, "Numerical Simulation of Coal Gasification in Entrained Flow Coal Gasifier," J. Fuel, 2006, vol. 85, pp.1935-1943, 2001.

[8] H. S. Tsan, W. L. William, S. Aammir, Y. Zhigang and Z. Jiang. "A New k- $\varepsilon$ Eddy Viscosity Model for High Reynolds Number Turbulent Flows," J. Computers Fluids, vol. 24, pp. 227-238, 1995

[9] W. F. Li, W. G. Cao, J. L. Xu, H. F. Liu, X. J. Liu, B. Huang, et al. "Large Scale Nitrogenous Fertilizer Industry," J. vol. 34, pp. 225-233, 2011

[10] J. L. Xu, Z. H. Dai, Q. H. Li, W. F. Li, F. C. Wang, et al. "Journal of Chemical Industry and Engineering," J. vol. 59, pp.53-57, 2008 